\title{
Labor Turnover Costs and the Behavior of Vacancies and Unemployment*
}

\author{
José I. Silva ${ }^{\dagger} \quad$ Manuel Toledo ${ }^{\ddagger}$ \\ Draft: March 23, 2005 \\ Preliminary
}

\begin{abstract}
It has recently been argued that the standard Diamond-Mortensen-Pissarides (DMP) search and matching model does not reproduce the cyclical fluctuations in vacancies and unemployment. Following the Insider-Outsider theory, we introduce post-match labor turnover costs in the model. This creates heterogeneity among matched workers. In particular, we consider two types of employed workers: new entrants and incumbents. We demonstrate that the extended DMP model helps to generate movements in those variables in response to productivity shocks of reasonable magnitude. The main mechanism is that with post-match turnover costs, the value of newly filled positions not only falls but also depends more heavily on entrants' net productivity. Thus, the value of a vacancy varies more with productivity shocks and thereby the number of vacancies in the economy fluctuates more. Moreover, when we compute the steady state effects of an increase in these post-mach turnover costs, the equilibrium unemployment rate turns out to be higher and the aggregate income of the economy is reduced.
\end{abstract}

Keywords: Labor Markets, Search, Matching, Insider-Outsider,Turnover costs, Business Cycles.

JEL Classifications: E24, E32, J31, J32, J41, J63, J64

\footnotetext{
${ }^{*}$ We wish to thank Michael Reiter, Mark Bils and Javier Vazquez for useful comments. We acknowledge financial support from the Central Bank of Venezuela.

${ }^{\dagger}$ Universidad Autónoma de Barcelona, Spain, and Central Bank of Venezuela. Email: jisilva@ecap.uab.es

${ }^{\ddagger}$ University of Rochester and Central Bank of Venezuela . Email: mtld@troi.cc.rochester.edu
} 


\section{Introduction}

The existence of labor market frictions in macroeconomic fluctuations has been increasingly recognized. In recent years, the Diamond (1982), Mortensen (1982), and Pissarides' (1985) (henceforth DMP) matching model has become the standard theory of equilibrium unemployment. However, a sequence of recent papers by Hall (2004a,b), Shimer (2004a,b), Fujita (2003), and Costain and Reiter (2003) have questioned the model's ability to match the U.S. data in at least one important dimension: the cyclical variations in unemployment and vacancies, in response to shocks of reasonable size.

One of the basic issues arising from this new research agenda is the need to investigate whether these empirical failures are due to a particular modeling route or to a failure inherent to the model itself. As it is well known, the DMP matching model has two fundamental elements. Fist, an exogenous matching function capturing the uncoordinated, time-consuming, and costly trade process for both firms and workers. The standard properties of this matching function essentially induce a negative relationship between unemployment and vacancies in the model. Such a feature matches a well known empirical relation captured by the Beveridge curve. Thus we can argue that this element works well as a basic ingredient of the model.

The other main element of the DMP matching model is how wages are determined. It is assumed that they are set through Nash bargaining at the individual level. Some of the studies questioning the DMP model precisely highlight the role of this assumption. They argue that Nash wage bargaining is the crucial reason why the model does not exhibit a good performance. ${ }^{1}$ Basically, the high flexibility of wages that comes from this scheme does not help to create the observed volatility in vacancies and unemployment. Just as Shimer (2004b) affirms:

"With wages determined by Nash bargaining, unemployment and vacancies are much less variable in the model that in the U.S. economy. A constant wage produces roughly the correct variance for these two key variables. In other words, this model provides some support, of a modern model of equilibrium unemployment, for the Keynesian notion that real wage rigidities exacerbate cyclical variations, so recessions are time when real wages are too high."

However, it is important to take into account that the DMP standard model is just a starting point of the search and matching approach to the equilibrium unemployment theory. As it has been emphasizes by Pissarides (2000):

"The model does not yet claim to be realistic or empirically implementable. At this stage many of the variables that are likely to be important in an empirical analysis of unemployment are left out."

Therefore, from an empirical perspective, it is important to extend this model in order to incorporate some features that may help to reduce the strong link between wages and productivity shocks or, alternatively, amplify the mechanism of transmission of the underlying shocks.

The objective of this study is to show that neither the matching function nor the

\footnotetext{
${ }^{1}$ Shimer (2004a,b) and Hall (2004a,b)
} 
Nash bargaining wage determination scheme are the reasons why the model does not produce large movements in vacancies and unemployment over the business cycle. Instead, introducing labor turnover costs in the DMP matching model helps to generate fluctuations in vacancies and unemployment observed in the data. We consider costs associated not only with hiring but also with training of new recruits and separation of employees, which we call post-match turnover costs. We also differentiate between two types of employed workers: new entrants ("outsiders") and incumbents ("insiders"). Entrants have a lower productivity, need training to become fully productive and, in contrast to incumbent employees, cannot force a favorable wage renegotiation in presence of significative separation costs. They nevertheless may eventually become incumbents.

The higher volatility of vacancies and unemployment results because with larger post-match turnover costs, the expected discounted profit or value of a new position falls, which reduces the labor demand (i.e., vacancies) and wages. In addition, new entrants find that their bargaining power has weaken which drives down their wages significatively and increases their net productivity. Simultaneously, incumbent employees' negotiating position has strengthen, pushing up their wages and reducing the value of a position filled with an incumbent. Consequently, entrants' net productivity accounts for a larger fraction of the expected return of a newly filled job. Therefore productivity shocks have a relatively greater impact on the value of a new vacancy and firms respond by opening more vacancies when a positive shock occurs.

We also study the long-run implications of our extended model. We find that training and separation costs have substantial effects on the long-run labor market outcomes, increasing unemployment and reducing the aggregate output of the economy. With higher post-match turnover costs, the value of a new job falls substantially. Thus, firms close vacancies inducing to a reduction in the exit rate from unemployment while the equilibrium in the labor market is restored. Given the separation rate, equilibrium unemployment rises.

The paper is organized as follows. Following the Insider-Outsider approach introduced by Lindbeck and Snower (1988), in section 2 we incorporate training and separation costs in the DMP standard model, prior to performing a first quantitative evaluation of this approach. In section 3 we simulate the model to check whether it can match some of the basic labor market facts for the U.S. economy. In section 4, we focus on the steady state effects of these post-match turnover costs in the equilibrium unemployment rate and in aggregate output. Finally, section 5 presents our conclusions.

\section{Turnover costs in the DMP model}

Turnover of productive workers is a major source of productivity and profit losses in the U.S. In the private sector, and according to the Job Openings and Labor Turnover Survey, during 2003 the monthly average of separations as referred to total employment was 3.4 percent. This means that around four out of ten employees in this sector left their company in 2003. This high rate is almost equal to the 
rate of hired workers. Estimates of the costs of employee turnover vary widely and depend on whether all costs are recognized, fluctuating between 25 percent and 200 percent of annual compensation for a leaving employee. ${ }^{2}$ The factors determining these turnover costs may include: efficiency of the incoming employee and associated coworkers; diminishing efficiency of the departing employee; productivity lost while the position is vacant; on-the-job costs including orientation and training; separation costs; employment processing costs; possible unemployment compensation costs; and out-of-pocket costs such as advertising and other recruiting expenses.

The costs associated with the dismissal of employees, the hiring and training of recruits make up the focal point of the Insider-Outsider theory. This deals with the existing conflict of interest between insiders and outsiders in the labor market. "Outsiders" are unemployed workers and "insiders" are incumbent employees whose position are protected by the presence of labor turnover costs. Basically, it examines how various types of these costs give insiders their market power, how they use this power to their own advantage, like pushing up their wages, and what this insider-outsider interaction implies for key labor market variables like employment and unemployment. Like Pissarides (2000), we will incorporate this approach into the DMP model building upon Shimer's (2004) stochastic version.

Several authors have included turnover costs of this nature into the DMP model. Some have done this in order to explain the cross countries differences in the unemployment rates. ${ }^{3}$ Others have used them for policy analysis. ${ }^{4}$ Here, we will focus in their consequences for the business cycle fluctuations. Basically, we argue that the labor market may respond differently to a shock from what the basic model without such costs predicts.

\section{$2.1 \quad$ The model}

This economy consists of a measure 1 of risk-neutral, infinitely-lived workers and a continuum of risk-neutral, infinitely-lived firms. Workers and firms discount future payoffs at a common rate $r$ and capital markets are perfect. In addition, time is continuous.

An aggregate shock hits the economy according to a Poisson process with arrival rate $\lambda$, at which point a new productivity $p^{\prime}$ is drawn from a distribution that depends on the current productivity level $p$.

Workers can be either unemployed or employed. Those who are employed can be either entrants $(e)$, receiving training, or incumbent employees $(i)$. It is assumed that entrants have a lower productivity relative to incumbent employees, $p_{e} \leq p_{i} \equiv p$. Unemployed workers are first considered entrants once they find a job.

There is a time-consuming and costly process of matching workers and job vacancies, which is captured by a standard constant returns to scale matching function $m(u, v)$, where $u$ denotes the unemployment rate and $v$ is the vacancy rate. Hence the rate at which unemployed workers find jobs, $f(\theta)$, and vacancies are filled, $q(\theta)$,

\footnotetext{
${ }^{2}$ See for example, Ahr (2000) and Branham (2000).

${ }^{3}$ See Millard and Mortensen (1997)

${ }^{4}$ See Pissarides (2000) for a textbook discussion.
} 
depend only in the vacancy-unemployment ratio $\theta$, where $f(\theta)=\theta q(\theta)$ and $f^{\prime}(\theta)>0$, $q^{\prime}(\theta)<0$. The unemployment rate increases when jobs are destroyed at an exogenous hazard rate $s$, and decreases when workers find jobs. Thus $u$ evolves according the following differential equation,

$$
\dot{u}=s(1-u)-f(\theta) u,
$$

The values of the different employment status - unemployed $(U)$, entrant $\left(W_{e}\right)$ and incumbent $\left(W_{i}\right)$ - are given by the following expressions:

$$
\begin{gathered}
r U=z+f(\theta)\left(W_{e}-U\right)+\lambda\left(\mathbb{E}_{p} U^{\prime}-U\right) \\
r W_{e}=w_{e}-s\left(W_{e}-U\right)+\iota\left(W_{i}-W_{e}\right)+\lambda\left(\mathbb{E}_{p} W_{e}^{\prime}-W_{e}\right) \\
r W_{i}=w_{i}-s\left(W_{i}-U\right)+\lambda\left(\mathbb{E}_{p} W_{i}^{\prime}-W_{i}\right) .
\end{gathered}
$$

If a worker is unemployed, she gets current value from leisure $z$, finds job at rate $f(\theta)$, which yields net value gain $W_{e}-U$, and receives shocks at rate $\lambda$ with expected capital gain $\mathbb{E}_{p} U^{\prime}-U{ }^{5}$ Employed workers earn the endogenous wage $w_{e}$ if an entrant or $w_{i}$ if an incumbent employee. Entrants and incumbents lose their job at rate $s$ with expected capital loss represented by the second term on the right hand side of expressions (3) and (4), respectively. Entrants become incumbent at rate $\iota$, which entails capital gain $W_{i}-W_{e}$. Finally, the last term of (3) and (4) represents the expected capital gain when an aggregate productivity shock occurs.

Firms have a constant returns to scale production technology that uses only labor. A job can be either filled or vacant. Job creation takes place when a firm and a worker meet and agree on an employment contract. However, before a position is filled, the firm has to open a job vacancy with flow cost $c$. Each filled job yields instantaneous profit equal to the difference between labor productivity and the wage, which is either $p_{e}-w_{e}$ for a just filled position or $p-w_{i}$ for a job filled with an incumbent employee. Let us assume that $p_{e}=p(1-\xi)$, where $0 \leq \xi \leq 1$ denotes the general training cost parameter or the productivity gap between entrants and incumbents. The interpretation of these assumptions is that both on-the-job training and learning by doing are needed before new employees can reach the productivity of existing workers in the firm.

Following Pissarides (2000), firms also face separation costs when a match is destroyed. In particular, firms lose $\gamma$ when a match with an incumbent worker is terminated. This cost is assumed to be fully wasted and not a transfer, reflecting, for example, layoff restrictions imposed by the government or efficiency losses due to the disruption to the regular flow of work among experienced employees. We assume for simplicity that separation of new entrants do not mean any cost to firms. There are a number of ways to justify this assumption. One is that in general new entrants have

\footnotetext{
${ }^{5}$ Here, $\mathbb{E}_{p} X^{\prime}$ represents the expected value of an arbitrary variable $X$ following the next aggregate shock conditional on the current state $p$. The aggregate shock yields capital gain $\mathbb{E}_{p} X^{\prime}-X$ for each value.
} 
not developed special organizational links with the rest of the employees or special ability relevant for the firm. It is also plausible to think that real-world firms may first want to try a new worker to make sure that she fits in their organization before offering her a long-term contract, which may have more firing restrictions than a short-term contract offered to new entrants.

Thus, the value of vacancies, $V$, and filled positions, $J_{e}$ and $J_{i}$, are represented by the following Bellman equations:

$$
\begin{gathered}
r V=\left\{\begin{array}{cc}
-c+q(\theta)\left(J_{e}-V\right)+\lambda\left(\mathbb{E}_{p} V^{\prime}-V\right) \equiv \Upsilon & \text { if } \theta>0 \\
\max \{0, \Upsilon\} & \text { if } \theta=0
\end{array}\right. \\
r J_{e}=p_{e}-w_{e}+s\left(V-J_{e}\right)+\iota\left(J_{i}-J_{e}\right)+\lambda\left(\mathbb{E}_{p} J_{e}^{\prime}-J_{e}\right) \\
r J_{i}=p-w_{i}+s\left(V-J_{i}-\gamma\right)+\lambda\left(\mathbb{E}_{p} J_{i}^{\prime}-J_{i}\right) .
\end{gathered}
$$

To close the model, we need first to incorporate two more assumptions. One is the free entry condition for vacancies: firms will open vacancies until the expected value of doing this becomes zero. Therefore, in equilibrium we must have

$$
V=0
$$

Since neither workers nor employers can instantaneously find an alternative match partner in the labor market and pre-match and post-match hiring decisions are costly, a match surplus exists. Some bargaining must be invoked to divide this surplus. Thus it is assumed that wages are set through Nash bargaining. The Nash solution is the wage that maximizes the weighted product of the worker's and firm's net return from the job match. The first-order conditions for entrants and incumbent employees yield the following two conditions,

$$
\begin{gathered}
(1-\beta)\left(W_{e}-U\right)=\beta\left(J_{e}-V\right) \\
(1-\beta)\left(W_{i}-U\right)=\beta\left(J_{i}-V+\gamma\right),
\end{gathered}
$$

where $\beta \in(0,1)$ denotes workers bargaining power relative to firms. Notice that the Nash condition for incumbents (10) has an extra term that depends on $\gamma$. The interpretation is that the firm's threat point when negotiating with an incumbent employee is no longer the value of a vacancy $V$ but $V-\gamma$ because now separation costs are relevant.

Using (2)-(10), we can now solve for the equilibrium wages as a function of the current state $p$ and $\theta$,

$$
\begin{gathered}
w_{e}=(1-\beta) z+\beta \theta c+\beta p(1-\xi)-\beta \iota \gamma \\
w_{i}=(1-\beta) z+\beta \theta c+\beta p+\beta r \gamma
\end{gathered}
$$


Introducing these labor turnover costs decreases the entrant wage (11) by a fraction of both the training costs and the separation costs. Since new workers are less productive due to training costs, the match surplus and thereby their wages are reduced. The negative effect of separation costs on entrants' wages is due to the fact that new employees may turn into incumbent workers with certain probability given by the hazard rate $\iota$ in which case firms become "liable" to these costs. Firms then perceive separation costs as an expected loss and, therefore, the expected match surplus is reduced. As for the incumbent workers, their wages (12) will be higher than new entrants' wages because there are no training costs and separation costs are now operational, which increase incumbents' "implicit" bargaining power.

The question that arises at this point is which the relevant value to determine the vacancy-unemployment ratio is, the value of a newly filled job $J_{e}$ or a position occupied by an incumbent $J_{i}$. Pissarides (2000) suggests to consider the former because the expected return of a new vacancy is calculated based upon the expected profit of a newly filled job. Similarly, Gottfries (1992) argues that the only firm's decision concerns how many new workers to hire. Accordingly we can define the equilibrium vacancy-unemployment ratio $\theta^{*}$ as

$$
\theta^{*}= \begin{cases}\hat{\theta} & \text { if } \hat{\theta} \geq 0 \\ 0 & \text { otherwise }\end{cases}
$$

where $\hat{\theta}$ satisfies the following forward-looking non-linear differential equation:

$$
\begin{aligned}
\frac{r+s+\iota+\lambda}{q(\hat{\theta})}+ & \left(\frac{r+s+\iota+\lambda}{r+s+\lambda}\right) \beta \hat{\theta}=\frac{(1-\beta)}{c}\left[p(1-\xi)-z+\frac{\iota(p-z)}{r+s+\lambda}\right]+ \\
& \lambda \mathbb{E}_{p} \frac{1}{q\left(\theta^{* \prime}\right)}-\frac{(1-\beta)}{c}\left(\frac{\iota \gamma s}{r+s+\lambda}\right)+\frac{\lambda \iota}{r+s+\lambda}\left(\frac{\beta \gamma+\mathbb{E}_{p} J_{i}^{\prime}}{c}\right) .
\end{aligned}
$$

\subsection{Comparative Statics}

One interesting question relates to whether this modified DMP matching model can explain the size of the business cycle fluctuations in two of its central elements, unemployment and vacancies. To explore this issue, we find the elasticity of the vacancyunemployment ratio with respect to labor productivity, $\varepsilon_{\theta p}$. For the moment, let us assume for simplicity that there is no aggregate shock, so $\lambda=0$, and $\theta>0$. Thus, from (14), we obtain

$$
\varepsilon_{\theta p}=\frac{p[(1-\xi)(r+s)+\iota]}{p[(1-\xi)(r+s)+\iota]-z(r+s+\iota)} \frac{[r+s+\beta f(\theta)] c+\frac{(1-\beta) \iota \gamma s q(\theta)}{(r+s+\iota)}}{[(r+s)(1-\eta)+\beta f(\theta)] c}
$$

where $\eta \in[0,1]$ is the elasticity of $f(\theta)$.

It is possible to show that this elasticity is increasing in both the training parameter $\xi$ and separation costs $\gamma$. To see this, notice that there is a direct effect and 
an indirect effect. The direct effect accounts for changes in $\varepsilon_{\theta p}$ keeping $\theta$ constant. It is straight forward to check that in both cases the direct effect is positive. The indirect effect works through changes in $\theta$. Looking at (14), it is easy to see that $\theta$ is decreasing in both parameters $\xi$ and $\gamma$. It is also possible to show that the second quotient on the right hand side of (15) is decreasing in $\theta$. Therefore, the indirect effect reinforces the direct effect.

The rate at which entrants become incumbents $\iota$ instead has an ambiguous effect on $\varepsilon_{\theta p}$. The direct effect is not clear. Although the first quotient in (15) is decreasing in $\iota$, the second is increasing. The indirect effect is also ambiguous since $\frac{d \theta}{d \iota}$ has no definite sign.

Even though the effect of $\iota$ on $\varepsilon_{\theta p}$ is not clear, the introduction of labor turnover costs seems to go in the right direction to improve the empirical performance of the DMP matching model. ${ }^{6}$ The intuition is as follows. Post-match labor turnover costs weaken new entrants' bargaining position and therefore their wages fall significatively. Moreover, the value of a newly filled position $J_{e}$ decreases which tends to reduce the number of vacancies and $\theta$, pushing down entrants' wages even more. As a result, their net productivity, $p_{e}-w_{e}$, increases relative to $J_{e}$. Consequently, productivity shocks have a relatively greater impact on the value of both a new match and a vacancy. Equilibrium then requires $\theta$ to fluctuate more with shocks. In other words, expansions are perceived as even better times and thereby firms open even more vacancies than in the case with $\xi=\gamma=0$.

\subsection{Calibration}

The issue of whether the model is now capable to match the U.S. data or in which extent it is able to explain relevant empirical facts is a quantitative question. To explore that we need to compute $\varepsilon_{\theta p}$ for reasonable parameter values. We calibrate the model to quarterly frequency as follows:

Fist, we normalize the productivity parameter $p=1$. Following Shimer (2004a), we set the real rate of interest $r=0.012$, which is consistent with available empirical work. An average separation rate $s$ around 9 percent each quarter is given by the new Job Openings and Labor Turnover Survey (JOLTS). Thus, we set $s=0.09$.

A matching function of the Cobb-Douglas form is assumed, $m(u, v)=\kappa u^{\alpha} v^{1-\alpha}$. Consistent with Blanchard and Diamond (1989), the elasticity of the matching function with respect to unemployment, $\alpha$, is 0.5 . Following the so-called Hosios (1990) condition for efficiency, the bargaining power $\beta$ is assumed to be equal to $\alpha$.

The quarterly average unemployment rate in the U.S. from 1951 to 2003 was 5.7 percent. Substituting this value along with $s$ in equation (1) for $\dot{u}=0$, we find an average job finding rate $f(\theta)$ equal to 1.49 , which implies an average monthly job finding probability for unemployed workers of $0.5 .^{7}$

Barron, Berger and Black (1997) report measures for the average duration of a vacancy, $1 / q(\theta)$, in the U.S. They work with four different data sets where employers

\footnotetext{
${ }^{6}$ Notice that as $\xi$ and $\gamma$ approach to zero, $\iota$ becomes irrelevant since $w_{e}$ and $J_{e}$ tend to approach $w_{i}$ and $J_{i}$, respectively.

${ }^{7}$ This value is very similar to that found by Hall (2004a).
} 
are asked a number of common questions about their recruiting activities. The most recent of these surveys, the 1993 Upjohn survey, reports an average duration of a vacancy of about one month. Consequently, we set $q(\theta)=3$.

Given $\alpha, q(\theta)$ and $f(\theta)$, we can find the average ratio of vacancies to unemployment $\theta$, and the matching function parameter $\kappa$ that captures the efficiency of the matching process. Thus, $\theta=f(\theta) / q(\theta)=0.497$ and $\kappa=f(\theta) / \theta^{1-\alpha}=2.11$. Prior to the beginning of the JOLTS in December 2000, there is no direct measure of vacancies for the U.S labor market. Fortunately, the early months of this new survey captured the labor market just around the last peak of employment after a long period of expansion during the 1990's, so the survey is able to describe the differences between a tight and a slack market. Along this line, we observed that during the last business cycle reported by the NBER, from March 2001 to November 2001, the average of vacancies to unemployment was 0.52 , a value similar to our calibrated $\theta .{ }^{8}$

We turn now to our parameter $z$. This parameter is crucial because a larger $z$ implies a smaller surplus, causing larger changes in hiring when $p$ changes. As equation (15) shows, $\varepsilon_{\theta p}$ goes to infinity as $z$ approaches to $p$. In Shimer (2004a), $z$ is set to 0.4 , capturing unemployment benefits (UB), which average 44 percent of the wage in the U.S. In contrast, Costain and Reiter (2003) choose $z=0.745$ to match the average semielasticity of the unemployment rate with respect to unemployment benefits $\varepsilon_{u z}$ equal to 2, their conservative interpretation of Layard and Nickell's (1999) results for 20 OECD countries during the period 1983-1994. However, although $\varepsilon_{u z}=2$ is close to the one often found in other cross-country studies, ${ }^{9}$ empirical results from a set of studies that use time series analysis for single countries are quite diverse. Moreover, Elmeskov, Martin and Scarpetta (1998) find different effects of unemployment benefits by group of countries when analyzing the role of labor market policies in 19 OECD countries during the period 1983-1995. In countries with low levels of public spending on active labor market policies (Australia, Canada, Italy, Japan, Spain, U.K. and U.S.), the semielasticity reported is twice as high as the average value found for the whole sample. Therefore, it appears that more econometric research is needed before considering this semielasticity as a sensible way to find an accurate value for the parameter $z$ in the model. As it has been concluded by Holmlund (1998) in his survey: "The weight of the evidence suggest that increased benefit generosity causes longer spells of unemployment and probably higher unemployment as well. But there remains a considerable degree of uncertainty regarding the magnitudes of these effects."

A $z$ greater than 0.4 can be consider reasonable since it should not only incorporate unemployment insurance but also the imputed real return from unpaid leisure activities, such as home production and recreation. In order to capture both components, we define $z=b+\varsigma$ as in Mortensen and Pissarides (1999), where $\varsigma$ represents the replacement rate and $b$ the value of leisure. We choose $\varsigma=0.37$ to match the average replacement rate of 44 percent observed in the U.S. as mentioned above, ${ }^{10}$

\footnotetext{
${ }^{8}$ We use Hall (2004a)data spreadsheet to obtain the average value of $\theta$.

${ }^{9}$ See Cahuc and Zylberberg (2004), p. 704.

${ }^{10}$ Since earnings turn out to average about 85 percent of output per worker according to Millard and Mortensen (1997), we have that $\varsigma=[(U B / w) \times(w / p)]=.44 \times 0.85=0.37$.
} 
and $b$ to satisfy equilibrium condition (14) for the average productivity level $p=1$.

Our final step is to find reasonable values for the labor turnover cost parameters $c, \iota, \xi$, and $\gamma$. To our knowledge few attempts have been made to measure these costs directly. Hamermesh (1993) reports few surveys on the costs of hiring and firing, and some careful attempts at inferring the accounting costs of turnover within particular firms. However, "[t]he diversity of the concepts behind these estimates makes their lack of agreement unsurprising. It is difficult to agree on what constitutes hiring costs, and how to measure those costs after a definition is settled upon. Most estimates ignore the cost of training new workers. None attempts to account for the cost of disruption to the flow of output that can occur as adjustments are made."11

Recently, Abowd and Kramarz (2000) have estimated the costs of hiring, training and separation of employees for a representative sample of French establishments. They claim (p. 21) that "[a]ll of the microeconomic evidence for France has counterparts in the U.S. that are not very different from those observed in France." For example, we should not expect significant differences in the costs of hiring and training a new employee in both countries, therefore we use the French data to lead us choose $c$ and $\xi$. This survey reports a very small hiring costs for the firm as a fraction of the annual labor costs per worker of about 3 percent. ${ }^{12}$ This can be translated to $c=0.30 .^{13}$

From the French survey can be inferred a considerably higher training costs of around 14 percent of annual labor costs, with a direct cost of 6 percent, ${ }^{14}$ and an indirect costs of 8 percent. ${ }^{15}$ Since we impute all training costs as a loss of productivity of new entrants which take on average $1 / \iota$ quarters to become incumbent workers, we have that $\xi / \iota=0.48 .^{16}$

Barron et al. (1997) document an average time spent on on-the-job training for new hires of about 83 hours during the first month and 168 hours during the first 3 months of work. ${ }^{17}$ This suggests that training activities extend somewhat beyond the first month on the job although they decrease in intensity. Moreover, on-the-job training is not the only element needed by a new employee to fill the productivity gap. It is reasonable to think that learning by doing is also part of the training process of a new worker. In the absence of any kind of estimate for $\iota$ in the literature that we

\footnotetext{
${ }^{11}$ Hamermesh (1993), p. 208.

${ }^{12}$ Reported employer expenses on job advertising, search firm fees, and compensation of applicants as distinct from employees, explicitly excluding training of newly hired employees.

${ }^{13} c / q(\theta)=0.03 \times 4$ quarters $\times 0.85=0.10$.

${ }^{14}$ Employer paid training expenditures exclusive of trainee labor costs and inclusive of payroll costs for instructors as well as all other direct material costs, such as the rental of equipment and space.

${ }^{15}$ The total number of hours of training paid by the firm when trainees were directly compensated by the firm, expressed in weekly wages.

${ }^{16} \xi / \iota=0.14 \times 4$ quarters $\times 0.85=0.48$. Notice that $p \xi / \iota$ represents the average total productivity loss during the entire training period.

${ }^{17}$ These activities are the number of hours spent by (a) specially trained personnel providing formal training to the most recent hired worker, (b) line supervisors and management personnel providing the new worker with informal individualized training and extra supervision, (c) coworkers away from other tasks in providing the new worker with informal individualized training and extra supervision, and (d) worker watching others perform tasks.
} 
are aware of, we think it is plausible to set $\iota=1$, which indicates that a new entrant takes on average 1 quarter to finish the training process and become fully productive. Furthermore, $\xi=0.48$, implying that entrants have roughly half the productivity of incumbent workers.

Taking into account the potential differences in labor laws and the levels of severance payments incurred by firms in France and the U.S., we should use an alternative source of information for the case of total separation costs. In France, separation costs represent a substantial fraction of annual labor costs, 60 percent on average according to the survey. This figure is consistent with the World Bank Firing Cost indicator reported for this country of around 7 months of wages. ${ }^{18}$ Using the same World Bank indicator, we observe a separation cost in the U.S. equivalent to 8 weeks of weekly wages. Therefore, we set $\gamma$ equal to $0.58 .^{19}$

With this set of parameters, we can now pin down our leisure parameter $b$ and, consequently, $z$. Using equilibrium condition (14), we have $b=0.3685$. Thus, $z=0.7385$, which is roughly the same as the one found by Constain and Reiter (2003). However, the semielasticity of unemployment with respect to unemployment benefits $\varepsilon_{u z}$ implied by our model is 3.1. That is, a rise in the replacement ratio by one percentage points increases the log of the unemployment rate by 0.031 . Unemployment becomes more responsive to the UB ratio than in the case of Costain and Reiter's (2003) conservative interpretation of Layard and Nickell's (1999) cross-countries study.

Table 1: Calibrated parameter values for the U.S. economy

\begin{tabular}{lcl}
\hline \hline Parameter & Value & Source \\
\hline Labor productivity $p$ & 1 & Quarterly normalization \\
Aggregate separation rate $s$ & 0.09 & JOLTS \\
Discount rate $r$ & 0.012 & Shimer (2004a) \\
Unemployment flow utility $z$ & 0.7385 & Equilibrium condition (14) \\
Job finding rate $f(\theta)$ & 1.49 & Equation (1) \\
Vacancy duration $\frac{1}{q(\theta)}$ & $\frac{1}{3}$ & Barron, Berger and Black (1997) \\
Elasticity of $f(\theta), \eta$ & 0.50 & Blanchard and Diamond (1989) \\
Unemployment rate $u$ & 0.057 & BLS \\
Workers' bargaining power $\beta$ & 0.50 & Hosios (1990) condition \\
Training cost $\xi$ & 0.48 & Abowd and Kramarz (2000) \\
Training process $\iota$ & 1 & Own assumption \\
Separation costs $\gamma$ & 0.58 & World Bank firing cost indicator \\
Hiring cost $c$ & 0.30 & Abowd and Kramarz (2000) \\
\hline
\end{tabular}

Notice that the evidence collected is revealing an important fact: post-match turnover costs are significatively higher than pre-match turnover costs. With our

\footnotetext{
${ }^{18}$ More in detail, the cited index measures the cost of advance notice requirements, and severance payments and penalties due when firing a worker, expressed in terms of weekly wages. More information can be found in http://rru.worldbank.org/DoingBusiness/ExploreTopics/

${ }^{19} \gamma=0.17 \times 4$ (quarters $) \times 0.85=0.58$.
} 
parametrization, the latter represent roughly about 9 percent of the former (i.e $\gamma+\xi / \iota=1.06>0.10=c / q(\theta))$. Thus, hiring decisions should depend crucially not only on pre-match but also on post-match turnover cost like the ones considered in this paper. This fact justifies incorporating the insider-outsider approach into the standard DMP model.

Using equation (15) without training and separation costs, $\xi=\gamma=0$, we obtain a elasticity of vacancies-unemployment ratio with respect to labor productivity, $\varepsilon_{\theta p}$, equal to 4.07, which represents 55 percent of the U.S. data value observed from 1951 to 2003 of $7.40 .^{20}$ Now, once post-match turnover costs are incorporated the elasticity obtained is 5.99. Clearly, incorporating training and separation costs in the DMP matching model helps to reproduce movements along a downward-sloping vacancyunemployment curve (the Beveridge curve) in response to a productivity shock of a reasonable magnitude.

\section{Simulation}

We now simulate both the basic DMP matching model and our extended version and turn to a discussion of their business cycle statistics. As in Shimer (2004a), the labor productivity satisfies $p=z+e^{y}\left(p^{*}-z\right)$, where $y$ is an Ornstein-Uhlenbeck process with persistence parameter $\zeta$ and standard deviation $\sigma$, and $p^{*}$ is the longrun average productivity. We set $\zeta=0.004$ and $\sigma=0.0376$ in order to reproduce the observed behavior of $p$. We also normalize $p^{*}=1$. We work with a discrete version of the stochastic process above. In particular, we use a discrete space state model like the one described by Shimer (2004a) with $2 n+1=1001$ grid points. ${ }^{21}$ The basic idea is that after every Poisson $(\lambda)$ shock the state variable $y$ and, in consequence, $p$ either moves one grid point up with probability $\frac{1}{2}\left(1-\frac{y}{n \triangle}\right)$ or down with probability $\frac{1}{2}\left(1+\frac{y}{n \triangle}\right)$, where $\triangle>0$ is the grid step size. In order to completely characterize the productivity process, we need to set $\lambda=n \zeta$ and $\triangle=\sigma / \sqrt{\lambda}$.

To simulate the model, we start with an initial productivity level and its corresponding vacancy-unemployment ratio given by the solution of equation (14). Then we compute the time until the arrival of the next shock, which is exponentially distributed with parameter $\lambda$. While the shock arrives, the unemployment rate changes according to equation (1). ${ }^{22}$ When the shock arrives, productivity varies following probabilities described above and thereby $\theta$ changes so that equation (14) is satisfied. At the end of each period (quarter) we record the level of each variable. We create 1000 sample paths of 1212 "quarters" and throw away the first 1000 of them in order

\footnotetext{
${ }^{20}$ This elasticity is obtained from the regression coefficient of the $\log (\theta)$ on $\log (p)$. We use filtered quarterly data for the U.S. for years 1951 through 2003. Vacancies are captured from the help-wanted advertising index constructed by the St. Louis FED. Unemployment is taken from the Bureau of Labor Statistics (BLS). Labor productivity $p$ is real average output per worker in the non-farm business sector, constructed by the BLS. As in Shimer (2004a), both $\theta$ and $p$ trends are an HP filter of the quarterly data with smoothing parameter $10^{5}$.

${ }^{21}$ Although Shimer (2004a) used 2001 grid points, we do not observe any significative change in his results when we reduce $n$ by half.

${ }^{22}$ To be more precise, we use a discrete version of equation (1).
} 
to obtain the U.S. post second world war period (212 quarters between 1951-2003). We detrend the generated data using an HP filter with $10^{5}$ smoothing parameter and, finally, we calculate the standard deviations, autocorrelation coefficients and correlation matrix.

Table 2 presents the summary statistics of the U.S. labor market, while tables 3 and 4 show the simulation results of the model without and with post-match turnover costs, respectively. ${ }^{23}$

Table 2: Summary statistics for the quarterly U.S. data, 1951 to 2003

\begin{tabular}{ccccccc}
\hline \hline & $u$ & $v$ & $\theta$ & $f(\theta)$ & $w$ & $p$ \\
\hline Standard Deviation & 0.191 & 0.210 & 0.390 & 0.176 & 0.014 & 0.021 \\
Quarterly Autocorrelation & 0.935 & 0.916 & 0.934 & 0.870 & 0.910 & 0.881 \\
\hline Correlation Matrix & & & & & & \\
$u$ & 1 & -0.879 & -0.963 & -0.917 & -0.104 & -0.391 \\
$v$ & & 1 & 0.969 & 0.785 & 0.019 & 0.356 \\
$\theta$ & & & 1 & 0.871 & 0.040 & 0.379 \\
$f(\theta)$ & & & 1 & 0.178 & 0.282 \\
$w$ & & & & & 1 & 0.240 \\
$p$ & & & & & & \\
\hline
\end{tabular}

Both versions of the model perform similarly and remarkably well in some dimensions. For example, the data simulation yields strong predictions with respect to some contemporaneous correlations. Foremost, it is the empirical correlation between unemployment and vacancies over the business cycle, the noted Beveridge curve. Similarly they generate the correct autocorrelation in the unemployment and job finding rates. However, they perform somewhat off-target in others dimensions. Among them, we have that the autocorrelation of vacancies is lower and the correlation among wages and the rest of the variables is much higher.

The most important difference between both versions of the model lies in the volatility of vacancies, unemployment and, consequently, $\theta$ and the job finding rate $f(\theta)$. As in Shimer (2004a), we find that in the standard model without training and separation costs the variables above show relatively low variability, with standard deviations that are at most 25 percent as volatile as in U.S. data. In contrast, our extended version of the matching model notably increases those standard deviations. Here, the fluctuations of $\theta, f(\theta)$ and $v$ are 57,63 and 80 percent as volatile as in the data. The standard deviation of unemployment also increases but in a much lower magnitude, from 0.038 to 0.064 .

Another interesting result comes from the relationship between wages, in particular, new employees' wages $w_{e}$, and vacancies. Even though $w_{e}$ is almost perfectly

\footnotetext{
${ }^{23}$ Table 2 reproduces Table 1 from Shimer (2004a,b), using the same period and statistical sources for each variable. Following a previous version of Shimer's paper (April 22, 2004a), the job finding rate, $f(\theta)$, is inferred from the level of unemployment and the mean unemployment duration. Basically, this measure is highly correlated with that used in his most recent version of the paper (December 5, 2004a) and, as he said, "had little effect on the results".
} 
Table 3: Simulation results. Basic DMP model (i.e, $\xi=\iota=\gamma=0$ )

\begin{tabular}{ccccccc}
\hline \hline & $u$ & $v$ & $\theta$ & $f(\theta)$ & $w$ & $p$ \\
\hline Standard Deviation & 0.038 & 0.046 & 0.082 & 0.041 & 0.021 & 0.021 \\
Quarterly Autocorrelation & 0.923 & 0.775 & 0.878 & 0.878 & 0.878 & 0.878 \\
\hline Correlation Matrix & & & & & & \\
$u$ & 1 & -0.902 & -0.970 & -0.970 & -0.962 & -0.962 \\
$v$ & & 1 & 0.980 & 0.980 & 0.970 & 0.970 \\
$\theta$ & & & 1 & 1.000 & 0.990 & 0.991 \\
$f(\theta)$ & & & 1 & 0.990 & 0.991 \\
$w$ & & & & 1 & 1.000 \\
$p$ & & & & & & 1 \\
\hline
\end{tabular}

Table 4: Simulation results. DMP model with post-match turnover costs

\begin{tabular}{cccccccc}
\hline \hline & $u$ & $v$ & $\theta$ & $f(\theta)$ & $w_{i}$ & $w_{e}$ & $p$ \\
\hline Standard Dev. & 0.064 & 0.165 & 0.222 & 0.111 & 0.021 & 0.035 & 0.021 \\
Quart. Autocorr. & 0.937 & 0.764 & 0.872 & 0.872 & 0.878 & 0.878 & 0.878 \\
\hline Corr. Matrix & & & & & & & \\
$u$ & 1 & -0.861 & -0.944 & -0.944 & -0.924 & -0.929 & -0.923 \\
$v$ & & 1 & 0.977 & 0.977 & 0.919 & 0.926 & 0.922 \\
$\theta$ & & & 1 & 1.000 & 0.948 & 0.954 & 0.951 \\
$f(\theta)$ & & & & 1 & 0.948 & 0.955 & 0.945 \\
$w_{i}$ & & & & & 1 & 0.999 & 0.999 \\
$w_{e}$ & & & & & & 1 & 0.999 \\
$p$ & & & & & & & \\
\hline
\end{tabular}

correlated with labor productivity as in the standard model, we observe a relative high volatility in both vacancies and the vacancy-unemployment ratio as opposed to the low volatility predicted by the basic DMP model.

We can explain this result as follows. Hall (2004a) and Shimer (2004b) have shown that introducing real wage rigidity in new matches, and thereby modifying the Nash bargaining wage determination scheme, improves the performance of the DMP matching model, generating the correct variance in unemployment and vacancies. More in detail, Shimer makes an extreme assumption replacing the Nash bargaining solution with a fixed wage, $w_{e, t}=\bar{w}$. Hall introduces a social norm in which wages remain in their previous level, $w_{e, t}=w_{e, t-1}$, as long as that level continues within the worker and employer reservation wages set in order to avoid inefficient matches. With these kind of rigidities, wages do not respond immediately to labor productivity shocks, implying that the net productivity in new matches, $p_{e}-w_{e}$, will be more procyclical, as well as vacancies and unemployment. Quantitatively, we should expect higher volatility in these variables with lower covariance respect to wages.

However, in our extended version of the model, the correlation coefficient between 
new entrants' wage and vacancies remains almost as high as in the basic model because there is no change in the Nash Bargaining scheme. Thus wages are as flexible as before. In contrast to Shimer's and Hall's papers, the amplification mechanism of the labor productivity shocks comes not from a more volatile net productivity but from its greater weight relative to the value of a newly filled position $J_{e}$, which in turns becomes more volatile. Therefore, we can argue that without introducing wage rigidities it is possible to improve the performance of the model. In particular, we have shown that incorporating additional features such as post-match turnover costs helps to generate the observed volatility of these key series.

To summarize, and in a similar way to the comparative static exercise that we did in previous section, the stochastic simulations of the DMP matching model confirms that post-match turnover costs such as training and separation costs help to amplify labor productivity shocks, inducing larger movements along a Beveridge curve, especially through a much more volatile behavior in vacancies.

\section{Steady State Analysis}

We now analyze the long-run impact of post-match turnover costs on the steady-state unemployment rate $u^{*}$ and net aggregate output defined as

$$
Q^{*}=(1-\xi) p n_{e}^{*}+p n_{i}^{*}+z u^{*}-c v^{*}-s n_{i}^{*} \gamma,
$$

where $\theta^{*}$ solve the equilibrium condition (14) with $\lambda=0 .{ }^{24}$

According to equations (1) and (16), the unemployment rate in the steady state is increasing in both $\xi$ and $\gamma .{ }^{25}$ The mechanism leading the economy to a higher long-run unemployment rate is as follows. With higher post-match turnover costs vacancies decrease because the expected profit of new hires falls. Therefore, workers find more difficult to find a match. Given the separation rates of the economy, the equilibrium unemployment rises.

As for the aggregate income $Q$, the effect of post-match turnover cost is ambiguous since the direct and negative effect of $\xi$ and $\gamma$ on $Q$ can be offset by the reduction in vacancies. Therefore, the direction of the impact depends on the value of the parameters in the model.

In order to asses the quantitative effect of changes in post-match turnover costs, we take our calibrated parameters in Table 1 and compute the long-run unemployment rate and the corresponding $Q^{*}$ for a number of different values of $\xi$ and $\gamma$. The results are shown in Table 5. We observe that in effect the unemployment rate is increasing in $\xi$ and $\gamma$. For example, in the absence of training and separation costs, $\xi=\gamma=0$, equilibrium unemployment rate would be 1.1 percentage point lower with respect to the average unemployment rate observed in the U.S. Similarly, given the training cost parameter, we observe that if separation costs in the U.S. were similar to those

\footnotetext{
${ }^{24}$ The values of $n_{e}^{*}$ and $n_{i}^{*}$ are obtained from their respective dynamic equations $\dot{n}_{e}=f(\theta) u-$ $(s+\iota) n_{e}^{*}$ and $\dot{n}_{i}=\iota n_{e}^{*}-s n_{i}^{*}$, with $\dot{n}_{e}=\dot{n}_{i}=0$.

${ }^{25}$ Strictly speaking, $u$ is non-decreasing in $\xi$ and $\gamma$ because for $p$ low enough, $\theta$ might be constant at zero for all $\xi$ and $\gamma$ greater than certain values.
} 
Table 5: Long-run effects of post-match turnover costs

\begin{tabular}{cccccc}
\hline \hline$\xi$ & 0.00 & 0.25 & 0.48 & 0.75 & 1.00 \\
\hline$\gamma$ & \multicolumn{5}{c}{ Unemployment Rate } \\
\cline { 2 - 6 } 0.00 & 4.6 & 4.8 & 5.0 & 5.5 & 5.7 \\
0.25 & 4.8 & 5.0 & & & \\
0.58 & 5.1 & & 5.7 & & \\
0.75 & 5.2 & & & 6.5 & \\
1.00 & 5.5 & & & \multicolumn{2}{c}{8.0} \\
\hline$\gamma$ & \multicolumn{1}{c}{ Aggregate } & Output & (as \% of $p)$ \\
\cline { 2 - 6 } 0.00 & 97.7 & 95.7 & 93.9 & 91.8 & 89.9 \\
0.25 & 95.7 & 93.8 & & & \\
0.58 & 91.8 & & 88.4 & & \\
0.75 & 91.3 & & & 86.0 & \\
1.00 & 89.9 & & & & 82.1 \\
\hline
\end{tabular}

reported in the French survey of approximately six months of wages $(\gamma \simeq 2)$, the steady-state unemployment rate would jump to 10.1 percent. This value is roughly the same to the average unemployment rate observed in France during the last 20 years (10.3 percent during the period 1984-2003). ${ }^{26}$

We also find that aggregate income increases when training and separations costs drop. With no post-match turnover costs $Q^{*}$ is 9.3 percent higher than what we found for the calibrated economy.

There is at least one more observation of interest from this exercise. When training and separation costs are changing simultaneously, the simulations suggest a nonlinear relationship among these post-match turnover costs and $u$. A rise in $\gamma=\xi$ from 0 to 0.25 increase unemployment by 0.4 percentage points. In contrast, an increment in these parameters from 0.75 to 1.00 would increase unemployment by 1.5 percentage points. Clearly, turnover of productive workers can be a significative source of productivity and profit losses in the U.S.

\section{Conclusions}

Following the insider-outsider approach, we have argued in this study that introducing labor turnover costs in the standard DMP search and matching model can help to generate substantial movements along a downward sloping Beveridge curve in response to shocks of a reasonable magnitude.

A first approximation trough a comparative static exercise shows that with reasonable parameter values associated with post-match turnover costs we can approximate the elasticity of the vacancies-unemployment ratio with respect to labor productivity to that observed in the U.S. data. A result that is confirmed in the simulations of the stochastic versions of the model, where unemployment and, especially, vacancies

\footnotetext{
${ }^{26}$ This rate is taking from the Bureau of Labor Statistic (BLS).
} 
fluctuate much more over the business cycle once training and separation costs are incorporated.

The result is mainly driven by the presence of lower "implicit" bargaining power in new entrants due to post-match turnover costs. Since entrants are the relevant workers in firms' hiring decisions and considering that (i) they need training before being fully productive as incumbent employees, and (ii) if workers agree to sing the contract then the firm becomes liable to separation costs, then a match will be conditional on the firm's agreement to incur in these costs. Thus, entrants absorb partially them by lowering their wages. Consequently, their net productivity $p_{e}-w_{e}$ increase. At the same time, the value of a newly filled position drops with these additional labor turnover costs. Therefore, labor productivity shocks have a greater impact on the value of vacancies and when a positive shock arrives firms have the incentive to create relatively more vacancies. Thus, unemployment fluctuates more over the business cycle.

Finally, we have explored the consequences of changes in the post-match turnover costs on the long-run labor market outcomes. Basically, an increase in either training or separation costs tends to raise the equilibrium unemployment rate and to lower the aggregate income of the economy. That is, with higher post-match turnover costs, the value of a new job fall and firms decide to close some of the existing vacancies. Given a constant job separation rate from firms, unemployed workers find more and more difficult to get a new job, inducing to an increment in the unemployment rate until the new equilibrium in the labor market is reached.

\section{A Appendix}

The Nash bargaining wages are given by the solution of the following maximization problem:

$$
\begin{gathered}
\max _{w_{e}}\left(W_{e}-U\right)^{\beta}\left(J_{e}-V\right)^{1-\beta} \\
\max _{w_{i}}\left(W_{i}-U\right)^{\beta}\left(J_{i}+\gamma-V\right)^{1-\beta}
\end{gathered}
$$

The first-order conditions for the maximization problem $(A 1)$ and $(A 2)$ are:

$$
\begin{gathered}
\beta\left(W_{e}-U\right)^{\beta-1}\left(J_{e}-V\right)^{1-\beta} \frac{\partial W_{e}}{\partial w_{e}}=-(1-\beta)\left(W_{e}-U\right)^{\beta}\left(J_{e}-V\right)^{-\beta} \frac{\partial J_{e}}{\partial w_{e}} \\
\beta\left(W_{i}-U\right)^{\beta-1}\left(J_{i}+\gamma-V\right)^{1-\beta} \frac{\partial W_{i}}{\partial w_{i}}=-(1-\beta)\left(W_{i}-U\right)^{\beta}\left(J_{i}+\gamma-V\right)^{-\beta} \frac{\partial J_{I}}{\partial w_{i}}
\end{gathered}
$$

Considering condition (8) and solving for $J_{e}$ and $J_{i}+\gamma$ in equations (6) and (7), and taking derivative with respect to $w$ we get 


$$
\begin{gathered}
J_{e}=\frac{p(1-\xi)-w_{e}+\iota J_{i}+\lambda \mathbb{E}_{p} J_{e}^{\prime}}{r+s+\iota+\lambda} \\
\Rightarrow \frac{\partial J_{e}}{\partial w_{e}}=-\frac{1}{r+s+\iota+\lambda}, \\
J_{i}+\gamma=\frac{p-w_{i}+(r+\lambda) \gamma+\lambda \mathbb{E}_{p} J_{i}^{\prime}}{r+s+\lambda} \\
\Rightarrow \frac{\partial J_{i}}{\partial w_{i}}=-\frac{1}{r+s+\lambda} .
\end{gathered}
$$

Solving for $W_{i}-U$ in equation (4), and taking derivatives with respect to $w_{i}$ yields

$$
\begin{aligned}
W_{i}-U & =\frac{w_{i}-(r+\lambda) U+\lambda \mathbb{E}_{p} W_{i}^{\prime}}{r+s+\lambda} \\
\Rightarrow \frac{\partial W_{i}}{\partial w_{i}} & =\frac{1}{r+s+\lambda} .
\end{aligned}
$$

Now, solving for $W_{e}-U$ in equation (3) and substituting (A9) into it we get

$$
\begin{aligned}
W_{e}-U & =\frac{w_{e}-(r+\lambda) U+\iota\left(W_{i}-U\right)+\lambda \mathbb{E}_{p} W_{e}^{\prime}}{r+s+\iota+\lambda} \\
& =\frac{w_{e}-(r+\lambda) U+\lambda \mathbb{E}_{p} W_{e}^{\prime}}{r+s+\iota+\lambda}+ \\
& {\left[\frac{\iota}{(r+s+\iota+\lambda)} \frac{\left(w_{i}-(r+\lambda) U+\lambda \mathbb{E}_{p} W_{i}^{\prime}\right)}{(r+s+\lambda)}\right] } \\
\Rightarrow \frac{\partial W_{e}}{\partial w_{e}} & =\frac{1}{r+s+\iota+\lambda} .
\end{aligned}
$$

Substituting $(A 6),(A 8),(A 10),(A 12)$ and $(8)$ into $(A 3)$ and $(A 4)$ and rearranging we obtain equation (9) and (10).

Now, notice that from the vacancy equation (5) and with $V=0$, we know that $J_{e}=c / q(\theta)$. By substituting that expression into (9), we get

$$
W_{e}-U=\frac{\beta}{1-\beta} \frac{c}{q(\theta)},
$$

which we can substitute into the unemployment value equation (2), taking into account that $f(\theta)=\theta q(\theta)$, and obtain

$$
(r+\lambda) U=z+\frac{\beta}{1-\beta} \theta c+\lambda \mathbb{E}_{p} U^{\prime}
$$

Then substituting equations $(A 7),(A 9)$ and (A14) into (10) and rearranging give us the incumbent's wage

$$
w_{i}=(1-\beta) z+\beta \theta c+\beta p+\beta r \gamma .
$$


The entrant's wage can be found by substituting $(A 5),(A 11),(A 14),(7)$ - after solving for $J_{i}$ - and (12) into (9),

$$
w_{e}=(1-\beta) z+\beta \theta c+\beta p(1-\xi)-\beta \iota \gamma .
$$

To obtain expression (14), equate $J_{e}=c / q(\theta)$ and (A5), then substitute (7) again, after solving for $J_{i}^{-},(11)$ and (12), and rearrange.

\section{References}

[1] Abowd, J. and Kramarz, F. 2000. The Costs of Hiring and Separations. Cornell University and CREST, mimeo.

[2] Ahr, P. and Ahr, Thomas 2000. Overturn Turnover. Causeway Publishing Company, St. Louis, Missouri.

[3] Barron, J., Berger, M. and Black, D. 1997. Employer Search, Training, and Vacancy Duration. Economic Inquiry, 35, 167-192.

[4] Braham, L. 2000. Keeping the People who Keep you in Business: 24 Ways to Hang on to Your Most Value Talent. Amacom

[5] Blanchard, O. and Diamond, P. 1989. The Beveridge Curve. Brookings Papers on Economic Activity, 1, 1-76.

[6] Cahuc, Pierre, and Zylberberg, A. 2004. Labor Economics. The MIT Press, Cambridge, Massachusetts.

[7] Costain J, and Reiter M. 2003. Business Cycles. Unemployment Insurance, and the Calibration of Matching models. Universidad Carlos III de Madrid, mimeo.

[8] Diamond, P. 1982. Wage Determination and Efficiency in Search Equilibrium. Review of Economic Studies, 49, 217-227.

[9] Elmeskov, J., Martin, J. and Scarpetta, S. 1998. Key Lessons for Labour Market Reforms: Evidence from OECD Countries' Experiences. Swedish Economic Policy Review, 5, 205-252.

[10] Fujita, S. 2003. The Beveridge Curve, Job Creation and The propagation of shocks. University of California San Diego, mimeo.

[11] Gotfries, N. 1992. Insider, Outsider, and Nominal Wage Contracts. Journal of Political Economy, 100, 252-270.

[12] Hall, R. 2004a. Employment Fluctuations with Equilibrium Wage Stickiness. Department of Economics Stanford University, mimeo.

[13] Hall, R. 2004b. Employment Efficiency and Sticky Wages: Evidence from Flows in the Labor Market. The Review of Economics and Statistic Lecture, August. 
[14] Hamermesh, D. 1993. Labor Demand. Princeton University Press, Princeton, New Jersey.

[15] Holmlund, B. 1998. Unemployment Insurance in Theory and Practice. Scandinavian Journal of Economics, 100, 113-141.

[16] Hosios, A. 1990. On the efficiency of Matching and Related Models of Search and Unemployment. Review of Economics Studies, 57, 279-298.

[17] Layard, R., and Nickell, S. 1999. Labor Market Institutions and Economic Performance. In Ashenfelter O. and Card D. (eds.). Handbook of Labor Economics, v.3c. Amsterdam: North Holland.

[18] Lindbeck, A. and Snower D.J. 1988. The Insider-Outsider Theory of Employment and Unemployment. Cambridge, MA, MIT Press.

[19] Millard, S. P. and Mortensen, D.P. 1997. The Unemployment and Welfare Effects of Labor Market Policy: A Comparison of the U.S. and the U.K. In Snower, D. and De la Dehesa G. (eds.). Unemployment Policy: Government Options for the Labor Market. Cambridge University Press, Cambridge.

[20] Mortensen, D. 1982. The Matching Process as a Non-Cooperative/Bargaining Game. in Mc Call, J. (ed.), The Economics Information and Uncertanty. Chicago, University of Chicago.

[21] Mortensen, D. and Pissarides, P. 1999. New Developments in Models of Serch in the Labor Market. in Ashenfelter O. and Card D., eds., Handbook of Labor Economics, vol 3:, 2567-2627. Amsterdam: Elsevier Science.

[22] Nickell, S. and Layard, R. 1999. Labor Market Institutions and Economic Performance. Handbook of Labor Economics, 3, 3029-3084.

[23] Pissarides, C. 1985. Short-Run Equilibrium Dynamics of Unemployment, Vacancies, and Real Wages. American Economic Review, 54, 1319-1338.

[24] Pissarides, C. 2000. Equilibrium Unemployment Theory. MIT Press, Cambridge, MA, second edition.

[25] Shimer, R. 2004a. The Cyclical Behavior of Equilibrium Unemployment and Vacancies. American Economic Review, March 2005 (Forthcoming).

[26] Shimer, R. 2004b. The Consequences of Rigid Wages in Search Models. Journal of European Economic Association (Papers and Proceedings),2, 469-479. 